Chronic Obstructive Pulmonary Diseases:

Journal of the COPD Foundation

COPD

FOUNDATION

\title{
Review
}

\section{Alpha-1 Antitrypsin Therapy for Autoimmune Disorders}

\author{
Sihong Song, $\mathrm{PhD}^{1}$
}

\begin{abstract}
Autoimmune diseases are conditions caused by an over reactive immune system that attacks self-tissues and organs. Although the pathogenesis of autoimmune disease is complex and multi-factorial, inflammation is commonly involved. Therefore, anti-inflammatory therapies hold potential for the treatment of autoimmune diseases. However, long-term control of inflammation is challenging and most of the currently used drugs have side effects. Alpha-1 antitrypsin (AAT) is an anti-inflammatory protein with a well-known safety profile. The therapeutic potential of AAT has been tested in several autoimmune disease models. The first study using a recombinant adeno-associated viral (rAAV) vector showed that AAT gene transfer prevented the development of type 1 diabetes (T1D) in the non-obese diabetic (NOD) mouse model. Subsequent studies showed that treatment with AAT protein prevented and reversed type 1 diabetes. The beneficial effects of AAT treatment have also been observed in other autoimmune disease models such as rheumatoid arthritis and systemic lupus erythematosus. This paper reviews the therapeutic application of AAT and discusses possible mechanisms of action in various autoimmune diseases.
\end{abstract}

Abbreviations: alpha-1 antitrypsin, AAT; adeno-assocaited viral, rAAV; type 1 diabetes, T1D; non-obese diabetic, NOD; interleukin, IL; lipopolysaccharide, LPS; serine proteinase inhibitor, SERPIN; neutrophil elastase, NE; alpha-1 antitrypsin deficiency, AATD; chronic obstructive pulmonary disease, COPD; tumor necrosis factor, TNF; B-cell activating factor, BAFF; rheumatorial arthritis, RA; systemic lupus erythematosus, SLE; granulomatisis with polyangittis, GPA; proteinase 3, PR3; collegen-induced, CI; human alpha-1 antitrypsin protein, hAAT; doxycycline, Dox; dendritic cells, DCs; type 1 interferon, IFN-1; plasmachloid DCs, pDCs; conventional DCs, cDCs

Funding Support: This work was supported in part by grants from National Institutes of Health, JDRF, University of Florida Research Foundation, Grifols Inc., and Alpha One Foundation.

Date of Acceptance: August 31, 2018

Citation: Song S. Alpha-1 antitrypsin therapy for autoimmune disorders. Chronic Obstr Pulm Dis. 2018;5(4):289-301. doi: https://doi. org/10.15326/jcopdf.5.4.2018.0131

1 Department of Pharmaceutics, College of Pharmacy, University of Florida, Gainesville

\section{Address correspondence to:}

\section{Sihong Song, $\mathrm{PhD}$}

Department of Pharmaceutics

College of Pharmacy University of Florida

Gainesville, FL 32610

Email: shsong@ufl.edu

Phone: 352-273-7867

\section{Keywords:}

alpha- 1 antitrypsin; alpha-1 antitrypsin deficiency; chronic obstructive pulmonary disease; autoimmunity; type 1 diabetes; rheumatoid arthritis; systemic lupus erythematosus

\section{Introduction}

Alpha-1 antitrypsin (AAT) is one of the major serum proteins in the circulation. It is mostly produced by hepatocytes, ${ }^{1}$ although other cells can also express AAT including epithelial cells, ${ }^{2,3}$ monocytes, ${ }^{4}$ macrophages, ${ }^{5}$ neutrophils, ${ }^{6}$ cornea $^{7}$ and pancreatic islet cells. ${ }^{8,9}$ The AAT gene (SERPINA1) is located on chromosome 14 and consists of 5 exons. The gene expression is complex and regulated by tissue-specific and pathological condition-specific processes (reviewed by Kalsheker et $\mathrm{al}^{10}$ ). First, there are multiple promoters that control AAT gene expression. For example, the liver-specific promoter is located upstream of exon $1 \mathrm{C}$, while the monocytespecific promoter is located upstream of the liver 
specific promoter (upstream of exon 1A). The gene's expression in other cell types is not well characterized. Second, AAT gene expression can be stimulated by inflammation or inflammatory mediators, such as IL(interleukin)-6 and lipopolysaccharide (LPS). ${ }^{11,12}$ Third, enhancers and repressors in the introns and downstream of the gene also play important roles in transcriptional regulation of the AAT gene. ${ }^{10}$ AAT protein biosynthesis and posttranslational modification are also complex and significantly influence its functions. AAT is a secretory glycoprotein that requires proper folding. AAT gene mutations (e.g., Glu342Lys) can lead to AAT protein misfolding, polymerization and inefficient secretion from the hepatocyte and can result in a conformational disease characterized by liver cirrhosis and pulmonary emphysema. Protein glycosylation, oxidation and other modifications can affect the half-life and functions of AAT. ${ }^{13}$ Because of the complexity of AAT gene regulation, protein biosynthesis and secretion, it is difficult to use serum AAT levels to predict and understand the biological roles of AAT.

Although AAT has been studied for over 60 years, the functions of AAT are not fully understood. AAT is a serine proteinase inhibitor (SERPIN) and inhibits neutrophil elastase (NE), proteinase 3, trypsin and cathepsin G, and many other enzymes and factors (e.g., tryptase, chymase, Nkallicreins and factor Xa) $\left(\right.$ reviewed by Bergin et $\left.\mathrm{al}^{6}\right)$. Most of these enzymes are involved in tissue damage or repair. AAT deficiency (AATD) is an autosomal genetic disorder resulting from a mutation in the AAT gene. AATD patients most commonly carry mutant $S$ or $Z$ alleles (e.g., $Z Z$, $S S$ or $S Z$ ) and have low serum AAT levels. The low levels of AAT are permissive to NE activity in the lung and likely the cause of emphysema. About 1\%-5\% of chronic obstructive pulmonary disease (COPD) patients may have AATD. ${ }^{14}$ The interaction of AAT with NE and the correlation between AATD and COPD have been intensively studied. AAT protein augmentation therapy for AATD has been clinically used for many years and has been proven to be safe and effective (reviewed by Petrache et $\mathrm{al}^{15}$ ). To protect the lung against degeneration in AATD patients, AAT gene therapy, using recombinant adeno-associated viral vector (rAAV) for muscle gene delivery, has been developed and shown to have protective effects in clinical studies. ${ }^{16,17}$ In addition to serving as a SERPIN, AAT also inhibits various enzymes and interacts with a number of inflammatory molecules. For example, it has been reported that AAT inhibits caspase- 1 and -3 , prevents apoptosis ${ }^{18-21}$ and has heme oxygenase- 1 suppressor activity. ${ }^{22}$ AAT also interacts with other important signaling molecules including IL-8, tumor necrosis factor (TNF)-a receptors (TNFR1 and TNFR2), ${ }^{23}$ fatty acids ${ }^{24}$ and retinoic acid. ${ }^{25}$ Moreover, many studies have shown that AAT treatment decreases gene expression of pro-inflammatory cytokines (e.g., IL-1 $\beta$, IL-6, TNF-a and B-cell activating factor [BAFF]) and other cellular molecules (e.g., RANK, integrin $\beta 3$, DC-STAMP and cFos), and enhances gene expression for the antiinflammatory cytokine IL-10. The intracellular effects of AAT may result from its interaction with cell surface receptors (e.g., CD14 or TNFRs) thereby affecting second messenger mediated signal transductions (e.g., cAMP and protein kinase $\mathrm{A})^{26}$ in addition to other unknown mechanisms. Furthermore, AAT can directly enter the target cells and interact with cellular proteins or factors. ${ }^{27}$

Besides emphysema and COPD, AATD has been shown to be associated with autoimmune and inflammatory diseases. The association of AAT with rheumatoid arthritis (RA) and systemic lupus erythematosus (SLE) was recognized soon after the discovery that AATD was linked to emphysema and COPD (reviewed by Breit ${ }^{28}$ ). Most of the early studies investigated the clinical associations of autoimmune diseases with AAT phenotypes and noted that the frequency of AAT-deficient phenotypes (e.g., PiMS or PiMZ) was higher in autoimmune disease patient populations including those with RA, SLE and psoriasis, although some controversy over the results was reported. ${ }^{29,30}$ It has been reported that AAT levels and activities in type 1 diabetes (T1D) patients were lower than that in healthy controls. ${ }^{31-34}$ In addition, the prevalence rates of inflammatory bowel disease and hyperthyroidism in AATD patients were found to be higher than that in the general population. ${ }^{35}$ AATD has also been shown to be associated with other inflammatory diseases including panniculitis ${ }^{36,37}$ and vasculitis (in particular granulomatosis with polyangiitis[GPA] formerly known as Wegener's granulomatosis). ${ }^{38}$ In GPA pathogenesis, overexpressed proteinase 3 (PR3) on the surface quiescent neutrophils is the target antigen of antineutrophil cytoplasmic antibodies, which can activate neutrophils and play 
an important role in the disease development. ${ }^{39}$ It has been shown that AAT can inhibit anti-PR3 antibody-induced neutrophil activation ${ }^{40}$ and that AAT activity is significantly decreased in GPA patients. ${ }^{41}$ Importantly, AATD patients developed autoantibodies against lactoferrin. ${ }^{23}$ The linkage of AAT to immunity was also indicated by an overreactive immune system in AATD or COPD patients (reviewed by $\operatorname{Cosio}^{42}$ ). For example, lymphoid follicles comprised of monoclonal B cells as well as $\mathrm{CD}^{+}$and $\mathrm{CD} 8^{+} \mathrm{T}$ cells, which are implicated in driving autoimmune diseases, were found in the lungs of AATD and COPD patients. ${ }^{43}$ Increasing evidence suggested a protective role of AAT against autoimmune disease development. However, the therapeutic effect of AAT for autoimmune diseases had not been reported until 2004. ${ }^{44}$ In addition, recent discoveries of AAT functions in different disease models provided better understanding of the protective effect of AAT in autoimmune disease.

AAT therapy has been tested in several disease conditions and has shown promising results and a strong safety profile. Phase I and II clinical studies using rAAV mediated gene therapy for AATD also showed no side effect from transgene expressed AAT. ${ }^{45-47}$ Several forms of AAT augmentation therapy, including intravenous infusion and inhalation of aerosolized AAT, have been used for many years to treat AATD and show no or minimal adverse events. The anti-inflammatory effect of AAT has also promoted the therapeutic evaluation of AAT in many other disease conditions including graftversus-host disease in humans, ${ }^{48}$ stroke in the rat model, ${ }^{49}$ osteoporosis in the mouse model ${ }^{50,51}$ and aging in Drosophila. ${ }^{52}$ This review will focus on the therapeutic applications of AAT in 3 autoimmune diseasesT1D, RA and SLE.

\section{Alpha-1 Antitrypsin Therapy for Type 1 Diabetes}

Type 1 diabetes (T1D) is an autoimmune disease affecting many young people worldwide. Currently, no cure is available, and the standard care for T1D is to manage glucose metabolism by exogenous insulin replacement therapy. T1D develops because of endogenous insulin insufficiency due to an autoimmune destruction of the insulin producing pancreatic beta cells. The factors responsible for
T1D are complex and involve a combination of genetic, environmental, and immunologic influences, all of which contribute to beta cell destruction and insufficient insulin secretion. Although T cell-driven autoimmunity plays an important role in disease development, innate inflammatory factors also contribute to the pathogenesis. ${ }^{53}$ Therefore, antiinflammatory therapy holds potential for the treatment of T1D.

The association of low AAT levels and activities with T1D development has been recognized, ${ }^{31-34}$ and the therapeutic effect of AAT as an anti-inflammatory therapy for the treatment of $\mathrm{T} 1 \mathrm{D}$ has been tested. Following a study using rAAV mediated IL-10 gene therapy, which showed a complete prevention of $\mathrm{T} 1 \mathrm{D}$ in the non-obese diabetic (NOD) mouse model, ${ }^{54}$ a rAAV vector expressing the human AAT gene (rAAV2CB-AAT) was tested for the therapeutic effect of AAT for T1D. AAT gene therapy resulted in significant prevention of T1D with $70 \%$ of treated NOD mice remaining diabetes free until 32 weeks of age. ${ }^{44}$ In addition to reducing insulitis, AAT gene therapy also reduced serum insulin autoantibody levels. These results promoted subsequent investigations using AAT as an anti-inflammatory drug for autoimmune and inflammation-related diseases. To further improve the protective effect of AAT gene therapy, the rAAV1$\mathrm{CB}-\mathrm{AAT}$ vector, known to be a more efficient rAAV serotype for muscle gene delivery, was used, and this formulation prevented diabetes in $90 \%$ of NOD mice, attenuated cell-mediated autoimmunity and altered T-cell receptor repertoire. ${ }^{55,56}$ Clinical grade AAT protein therapy has also shown to prevent or reverse diabetes in NOD mice. ${ }^{57,58}$ While repeated injections of human AAT may induce a severe immune response (fatal anaphylaxis) in the NOD mouse model, ${ }^{59}$ it can be avoided by kinetics optimization to lower AAT levels at 30 minutes after injection, and the animals can become tolerant to long-term treatment. ${ }^{57}$ Unlike rAAV- medicated AAT gene therapy, which generally takes weeks for peak transgene expression, AAT protein therapy can provide a quick protective effect. Therefore, AAT protein therapy is not only capable of preventing, but also reversing newly onset $\mathrm{T} 1 \mathrm{D}$ in NOD mice. ${ }^{57,58}$ AAT protein therapy may also be useful in finding the critical therapeutic windows for reversal of T1D. ${ }^{53}$ In addition to reducing cytokine production (e.g., BAFF), ${ }^{57}$ it has been shown that AAT treatment can inhibit cellular caspase-3 activity, 
protect pancreatic beta cells from cytokine or druginduced apoptosis and enhance insulin secretion from beta cells. ${ }^{27,60}$ Based on these preclinical results and the clinical evidence showing impaired AAT activity in T1D patients, clinical studies using AAT for the treatment of T1D have been conducted. A recent report showed that AAT was well tolerated and safe in patients with new onset of $\mathrm{T} 1 \mathrm{D}$ and suggested a higher AAT dose (>90 mg/kg/week) may be needed for optimal therapeutic effect. ${ }^{61}$

Allogenic transplantation of islet cells has been considered as a treatment for T1D. However, immune rejection and recurrent autoimmunity leading to transplant cell death has slowed the progress. Given the anti-inflammatory and cytoprotective effect of AAT, AAT has been tested as an anti-rejection agent in islet transplantation studies. Results from these studies showed that AAT treatment significantly prolonged islet allograft survival and induced immune tolerance in mouse models. ${ }^{62-64}$ The results from islet transplantation studies have provided important insights for understanding AAT functions and prompting studies of AAT as an antirejection agent in other organ transplantations.

\section{Alpha-1 Antitrypsin for Rheumatoid Arthritis}

Rheumatoid arthritis (RA) is a common systemic autoimmune disease characterized by chronic joint inflammation and destruction. The associated pain and disability severely affect the quality of life of RA patents. While the pathogenesis of RA is complex, inflammation clearly plays an important role in the disease development. Therefore, anti-inflammatory agents have constituted the principle treatment option.

To evaluate the therapeutic potential of AAT on RA, AAT protein and gene therapies have been tested in the type II collagen-induced (CIA) arthritis mouse model. Results from those studies showed that both therapies delayed arthritis development, and reduced serum autoantibody against collagen II and BAFF levels. ${ }^{65}$ It is important to notice that repeated injections of human AAT protein (hAAT) in CIA mice induced high levels of anti-hAAT antibodies but did not lead to anaphylaxis as observed in NOD mice. The immune response to hAAT raised concerns about the nonespecific effect from foreign protein-induced immune response that may complicate interpretation of the results. As observed in the NOD model, ${ }^{66}$ rAAV8mediated human AAT gene therapy in CIA did not induce anti-hAAT antibodies and resulted in a similar, if not better, protective effect. ${ }^{65}$ These results together clearly rule out the concern of non-specific effect and indicate that the protective effects are hAAT specific. Another AAT gene therapy system has also been developed, in which AAT gene expression in rAAV vector is up-regulated by doxycycline (Dox). Since Dox also has anti-inflammatory effects, this system is considered to be a drug (Dox)-inducible, combination therapy. The application of this system in the CIA mouse model reduced arthritis development and joint damage. ${ }^{67}$

Consistent with the protective effects of AAT observed in animal models, clinical correlation between AAT and RA has been reported. ${ }^{68-70}$ A recent study showed that RA patients carrying a mutant AAT gene (PiMZ phenotype) had higher levels of anticitrullinated peptide autoantibodies. ${ }^{71}$ In addition, RA patients have been reported to develop autoantibodies against carbamylated AAT. ${ }^{72}$ These results suggest a potential role for AAT in modulating RA autoimmunity.

\section{Alpha-1 Antitrypsin for Systemic Lupus Erythematosus}

Systemic lupus erythematosus (SLE) is a lifethreatening autoimmune disease affecting millions of people (mostly women) worldwide. The disease can cause tissue damage in multiple organs including kidney, brain, skin and heart. ${ }^{73}$ Currently, there is no cure for SLE. The treatment options are limited to nonsteroidal anti-inflammatory drugs, antimalarial drugs, corticosteroids and immune suppressants to control the symptoms and reduce tissue damage. However, these drugs have many debilitating side effects. Therefore, development of a safe and effective therapy for SLE is needed. Mounting evidence shows that dendritic cells (DCs) and type I interferon (IFN-I) play critical roles in initiating and maintaining the disease. $^{74}$ Plasmacytoid DCs (pDCs) that link innate and adaptive immunity are the major cell source for the production of IFN-I in response to autoantigens in the form of immune complexes. IFN-I can activate monocytes or conventional DCs (cDCs) to produce $\mathrm{BAFF}$, which is a key factor stimulating $\mathrm{B}$ cells to produce autoantibodies. In addition, activated DCs can present autoantigens and induce $\mathrm{T}$ cell differentiation 
by up-regulating major histocompatibility complex class II and costimulatory molecules for adaptive immune responses. Activated pDCs can also indirectly affect $\mathrm{T}$ cells by producing inflammatory cytokines (e.g., IL-12, IL-6, TGF- $\beta$, TNF-a, IFN-I). Therefore, targeting DCs by inhibiting their activation and function has a great potential for controlling autoimmunity and the development of SLE. ${ }^{75}$

Although serum levels of AAT, an acute-phase protein reactant, can be elevated in SLE, ${ }^{76}$ the therapeutic effect of AAT has not been tested until recently. Shapria et al discovered that treatment with an anti-inflammatory peptide (a H2A histone fragment) increases the levels of C-terminal fragment (termed UBE, 36 AA, 378413) of AAT in C57BL/6 mice. ${ }^{77}$ Injection of UBE into MRL/lpr mice, a spontaneous lupus mouse model, reduced proteinuria, renal damage, and the levels of autoantibodies against double stranded DNA (antidsDNA) and cytokines (IL-17 and IL-12). Likewise, a recent study showed that treatment with clinical grade human AAT inhibited mouse bone marrow derive DC maturation and cytokine secretion including TNF-a, IL-1 $\beta$, and importantly, IFN-I. ${ }^{78}$ The treatment also lowered serum levels of lupus specific autoantibodies, anti-dsDNA IgG and anti-nuclear antibodies. Importantly, the treatment attenuated lupus nephritis in MRL/lpr mice.

\section{Alpha-1 Antitrypsin Insufficiency}

A common question regarding the use of AAT to treat autoimmune disease is why AAT treatment is needed since most patients with autoimmune diseases are not AAT deficient. Several studies have attempted to find a correlation between AAT levels and disease development or to use AAT as a biomarker. Some studies showed significantly higher or lower AAT levels in patients than in healthy controls, while other studies show no significant difference. ${ }^{70}$ These inconsistencies may be due to differences in the sample size, detection methods or patient populations. In addition, several other factors, which may contribute to AAT insufficiency, should be considered when investigating the protective role of AAT in autoimmune diseases.

\section{First, Insufficient Alpha-1 Antitrypsin Production}

The AAT gene is regulated by inflammatory mediators (e.g., IL-6), while AAT, in turn, can suppress inflammatory cytokine gene expression. It has been recently reported that AAT treatment can down-regulate endogenous AAT gene (SERPINA1) expression in human hepatocytes. ${ }^{79}$ Normally, this feedback system works well to control inflammation. However, in the setting of autoimmune or chronic inflammatory disease, this system may be imbalanced. On the one hand, chronic inflammation may exhaust the up-regulated AAT gene expression. On the other hand, inflammatory molecules (e.g., cytokines) further upregulate inflammatory genes thereby, counteracting the cytokine-inhibiting action of AAT (Figure 1). It has been reported that endogenous AAT (mouse AAT) levels in commonly used T1D (NOD) mice are lower than in normal mice (C57BL/6), ${ }^{56}$ and mouse AAT levels in lupus mice (MRL/lpr) are gradually decreased as the disease develops. ${ }^{78}$ These results provide evidence for the insufficiency of AAT in these disease conditions and the necessity of AAT therapy.

\section{Second, Insufficient Alpha-1 Antitrypsin Function}

AAT protein can be chemically modified or cleaved leading to loss of function. Mature AAT is a single polypeptide chain of 394 amino acids with 3 N-glycosidically linked oligosaccharides at 46, 83 and $247 .^{80,81}$ AAT glycans are extremely important for AAT half-life in circulation and for exerting antiinflammatory function. ${ }^{82,83}$ In certain pathological conditions, AAT glycosylation changes can be detected. ${ }^{84}$ A recent study showed that glycosylation of AAT was changed to heavily sialylated forms during the resolving phase of community-acquired pneumonia. Importantly, the more negatively charged AAT glycoforms (M0 and $\mathrm{M} 1$ ) are more effective in binding to IL-8 and in inhibiting neutrophil migration. ${ }^{85}$ In high glucose conditions in vitro and in plasma of diabetes patients, the proteinase inhibitory capacity of AAT can be significantly lower. ${ }^{31}$ AAT has 9 methionines and is sensitive to reactive oxidant species. Oxidization on methionines 351 and 358 at the reaction center can lead to the loss of anti-NE activity. ${ }^{86}$ In addition, inactivated oxidized AAT were detected in synovial fluid of RA patients. ${ }^{87}$ In human plasma and in atherosclerotic lesions, the oxidized AAT can also interact with low-density lipoprotein and form a complex, which can be rapidly degraded by macrophages. ${ }^{88}$ AAT is a key substrate of matrix metalloproteinase $9,{ }^{89}$ which is involved in a variety of autoimmune diseases (reviewed by Ram ${ }^{90}$ ). In RA 


\section{Figure 1. AAT Insufficiency}

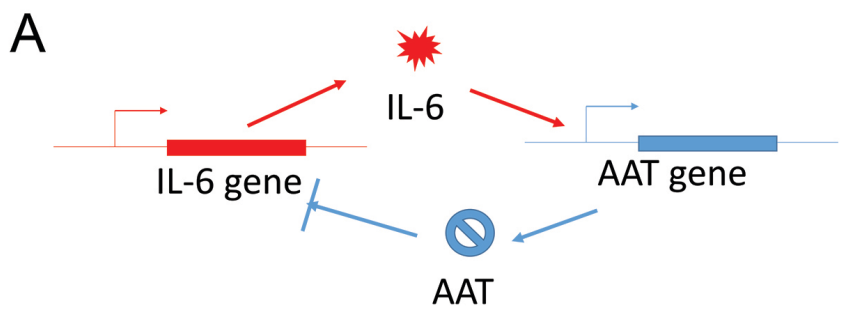

B
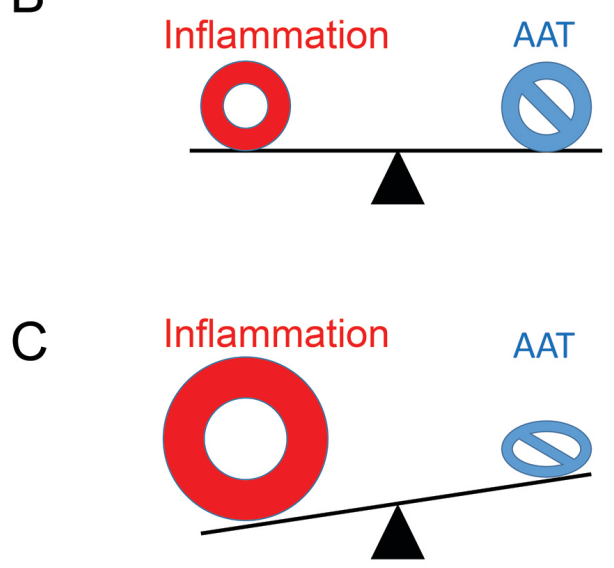

A. AAT can inhibit gene expression and protein production of inflammatory mediators (e.g., IL-6) and these molecules can enhance AAT gene expression. B. In normal conditions, the anti-inflammatory effect of AAT can counter-balance the inflammatory effect (meet the demand). C. In a diseased condition, more anti-inflammatory activities may be required or the activity of AAT may be relatively lower (loss of AAT functions). Therefore, the AAT level or activity may not be enough to counter-balance the high demand thus creating AAT insufficiency. The anti-inflammatory demand includes: (1) the inhibition of proteinases; (2) the suppression of inflammatory gene expression; (3) the blockage of inflammatory signaling; (4) the control of autoantibody production; (5) the control of DC activation.

$\mathrm{AAT}=$ alpha- 1 antitrypsin; $\mathrm{IL}=$ interleukin; $\mathrm{DC}=$ dendritic cells

patients, some AAT can be carbamylated and lead to the generation of autoantibodies against carbamylated AAT. ${ }^{72}$ Hence, the loss of AAT function in autoimmune disease conditions may be the reason that AAT therapy is needed.

\section{Third, Pathological Alpha-1 Antitrypsin Insufficiency}

In certain pathological conditions, the demand for AAT locally at inflammation sites (e.g., pancreatic islet in T1D, joints in RA or kidney in SLE) may increase and such demand may not be met by a commensurate increase in circulating AAT. For example, in human rheumatoid synovial fluid, AAT is oxidized and has a lower activity leading to a relative AAT insufficiency locally. ${ }^{87}$ The set-specific (or local) AAT insufficiency (rather than deficiency) may be the reason that AAT treatment is beneficial in autoimmune diseases. The same concept may also apply to other disease conditions including stroke, osteoporosis and obesity. $49,51,52,91$

\section{Possible Mechanisms}

Since AAT is a multifunctional protein, multiple mechanisms may be involved in the protective or therapeutic effect of AAT in autoimmune disease. Although the mechanisms are not entirely understood, increasing evidence supports the following theories (Figure 2).

\section{Inhibition of Proteinases}

Tissue damage mediated by proteinases is a major characteristic in autoimmune diseases. The inhibitory effect of AAT on proteinases may contribute to tissue protection. Recent studies have shown that an imbalance between NE and AAT has a pathogenic role in autoimmune disease conditions. ${ }^{91}$ It has been reported that animals and humans with T1D have elevated circulating protein levels and enzymatic activities of $\mathrm{NE}$ and $\mathrm{PR} 3$ suggesting that reduced AAT is responsible for increased proteinase activity. ${ }^{92}$ An imbalance between NE and AAT has been reported to alter insulin sensitivity, tissue inflammation and energy expenditure. ${ }^{91}$ In addition, anti-caspases and anti-MMP activities can also contribute to cell and tissue protection. ${ }^{18}$ As a proteinase inhibitor, AAT can also influence inflammatory molecule maturation and activation. For example, AAT inhibition of caspase-1 can in turn inhibit IL-1 $\beta$ activation since the conversion of the precursor of IL-1 $\beta$ to its active form involves cleavage by caspase- $1 .^{21}$

\section{Interaction with Inflammation Mediators}

It has been shown that AAT directly interacts with IL-8 and TNF-a receptors and blocks their actions. ${ }^{23,32}$ A recent study has shown that AAT can directly bind to and inhibit the activity of leukotriene B4. ${ }^{93}$ Leukotriene B4 plays an important role in neutrophil infiltration and is associated with many inflammatory disorders including COPD, RA and psoriasis. ${ }^{94-97}$ AAT can also bind plasma fatty acids and induce gene expression of angiopoietin-like protein 4, a potent anti-angiogenic and anti-inflammatory factor, through 


\section{Figure 2. Summary of Alpha-1 Antitrypsin Functions Against Autoimmune Disease}

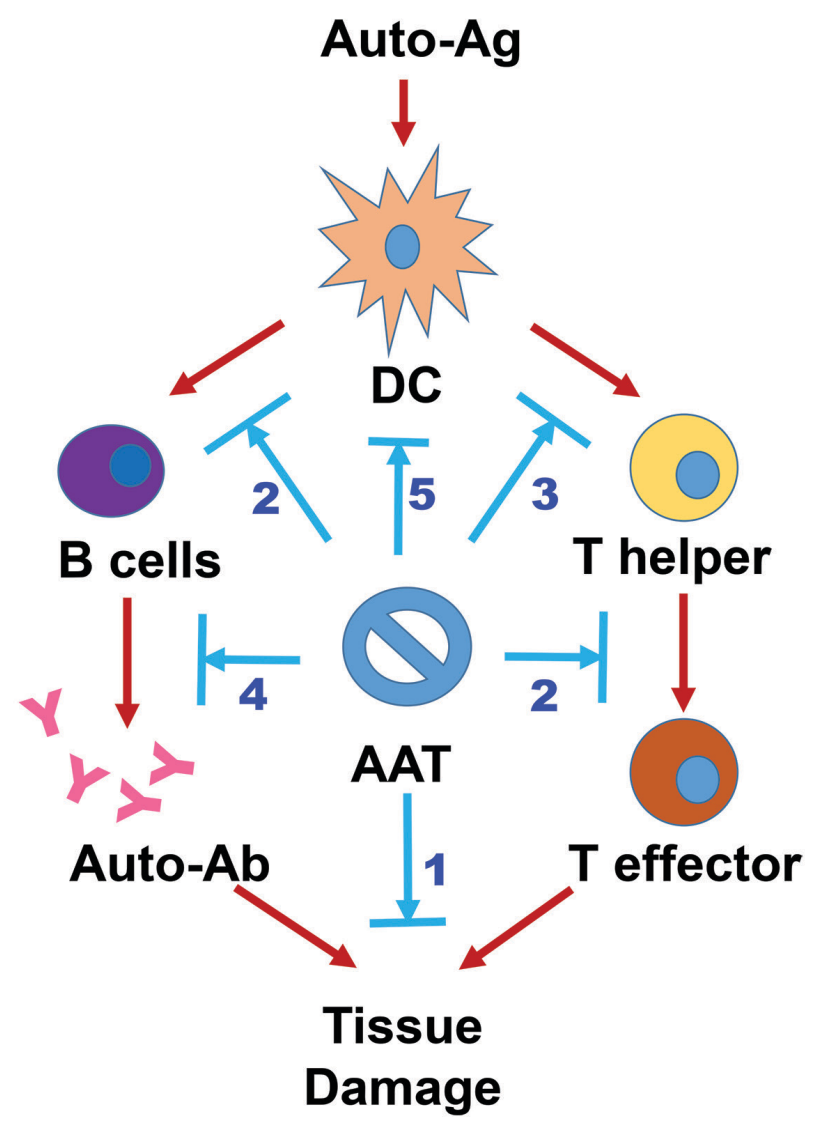

(1) AAT protects against tissue damage by inhibiting proteinases. (2) AAT blocks inflammatory signaling by interacting with inflammatory molecules, which may activate B cells and T cells. (3) AAT reduces inflammatory response by altering inflammatory gene expressions in various cell types including dendritic cells and monocytes. (4) AAT reduces autoantibody production from $\mathrm{B}$ cells. (5) AAT inhibits DCs activation and functions.

AAT=alpha- 1 antitrypsin; $\mathrm{DC}=$ dendritic cells; Auto $\mathrm{Ab}=$ autoantibody; Auto $\mathrm{Ag}=$ autoantigen

the per-oxisome proliferator-activated receptordependent pathway. ${ }^{24}$ In plasma of T1D patients, AAT can interact with heat shock protein 70 and glucoseregulated protein $94,98,99$ which play pathological roles in the disease development by binding and delivering antigens. ${ }^{100}$ These functions are completely independent of the anti-proteinase activity and play a critical role in immune regulation.

\section{Alteration of Gene Expressions}

It has long been observed that AAT treatment can inhibit gene expression of inflammatory molecules including IL-6, IL-1 $\beta$, TNF- $\mathrm{a}$ and IFN-I. The molecular mechanism of this action is elusive. It is believed that AAT can enter the target cell and interact with cellular factors. ${ }^{27}$ A recent study using RNA-sequencing has shown that AAT treatment inhibits irradiationinduced expression of 33 genes including IL-6, IL-8, CCL2, CCL 7, IL 1Beta, CXCL 1, CXCL2, and CXCL6 even 3 days after AAT withdrawal. ${ }^{52}$ Bioinformatics analyses indicate that most of these genes are related to innate immunity and are regulated by NF-kB.

\section{Suppression of Autoantibody Production}

As mentioned above, multiple studies have shown that AAT treatment significantly reduces autoantibody levels in T1D, RA and lupus mouse models. ${ }^{44,65,78}$ Interestingly, the inhibitory effect of AAT on autoantibody production has also been observed in AAT deficient patients. ${ }^{23}$ Since autoantibodies are a hallmark of various autoimmune diseases, this inhibitory effect clearly demonstrates the specific role of AAT in regulating autoimmunity. Although the effect of AAT on cytokine production and function may contribute to reducing autoantibody production, more mechanisms, such as AAT's direct effect on B cells, may be involved in the inhibition of autoantibody productions. It has been reported that pro-, pre-, and immature B cell population were reduced in aged AAT transgenic mice compared to age-matched wild type mice, indicating the effect of AAT on the fitness of B cell progenitor populations. ${ }^{101}$

\section{Attenuation of DC Maturation and Function}

DCs play a critical role in the development of autoimmune diseases. It has been shown that AAT treatment significantly inhibits LPS (TLR4 agonist) or CpG (TLR9 agonist) induced $\mathrm{cDC}$ and pDC maturation and the cytokine secretion (e.g., IFN-I) in vitro. ${ }^{78}$ Similarly, AAT treatment in lupus prone MRL/lpr mice attenuates bone marrow-derived DC differentiation and maturation. ${ }^{78}$ AAT treatment can also promote IL-10 producing tolerogenic DCs. ${ }^{102}$ The effect of AAT on DCs may provide the central mechanism for regulatory benefits in autoimmune disease conditions. In addition, the effects of AAT on other cell types including neutrophils and macrophages (reviewed by Bergin $^{6}$ ) are certainly important for the therapeutic benefits. It should be noted that there may be crosstalk among the aforementioned mechanisms. For 
example, AAT interacting with TNF-a receptors can block TNF- a signaling leading to the inhibition of downstream gene expression in DCs.

\section{Future Directions and Challenges}

Increasing data from preclinical studies has shown the therapeutic potential of AAT for autoimmune diseases. On one hand, more mechanistic studies are needed to understand the function of AAT. The challenge for this direction is to dissect AAT functions and identify the major targets and pathways in different conditions. Overcoming this challenge may require the development of new animal and cell models, and application of advanced technologies, such as RNA-sequencing and proteomics. On the other hand, more translational and clinical studies are required to confirm the therapeutic effect of AAT. The challenges for this direction mostly come from the complex nature of autoimmune diseases including the variations in disease symptoms, staging, and genetic and environmental factors. It is possible that AAT therapy will be effective in some patient populations, but not others. Cumulative clinical data will provide useful information for the precision application of AAT therapy.

\section{Acknowledgements}

The author acknowledges Drs. Adam Wanner, Mark Brantly, Amanda Posgai, and Mark Atkinson as well as Ahmed Elshikha and Ye Yuan for their suggestions.

\section{Declaration of Interest}

The author has no relevant conflict of interest to declare. 


\section{References}

1. Rogers J, Kalsheker N, Wallis S, et al. The isolation of a clone for human alpha 1-antitrypsin and the detection of alpha 1-antitrypsin in mRNA from liver and leukocytes. Biochem Biophys Res Commun. 1983;116(2):375-382.

doi: https://doi.org/10.1016/0006-291X(83)90532-6

2. Cichy J, Potempa J, Travis J. Biosynthesis of alpha1-proteinase inhibitor by human lung-derived epithelial cells. J Biol Chem. 1997;272(13):8250-8255.

doi: https://doi.org/10.1074/jbc.272.13.8250

3. Molmenti EP, Perlmutter DH, Rubin DC. Cell-specific expression of alpha 1-antitrypsin in human intestinal epithelium. J Clin Invest. 1993;92(4):2022-2034.

doi: https://doi.org/10.1172/JCI116797

4. Carroll TP, Greene CM, O'Connor CA, Nolan AM, O'Neill SJ, McElvaney NG. Evidence for unfolded protein response activation in monocytes from individuals with alpha-1 antitrypsin deficiency. J Immunol. 2010;184(8):4538-4546. doi: https://doi.org/10.4049/jimmunol.0802864

5. van 't Wout EF, van Schadewijk A, Savage ND, Stolk J, Hiemstra PS. Alpha1-antitrypsin production by proinflammatory and antiinflammatory macrophages and dendritic cells. Am J Respir Cell Mol Biol. 2012;46(5):607-613.

doi: https://doi.org/10.1165/rcmb.2011-0231OC

6. Bergin DA, Hurley K, McElvaney NG, Reeves EP. Alpha-1 antitrypsin: a potent anti-inflammatory and potential novel therapeutic agent. Arch Immunol Ther Exp (Warsz). 2012;60(2):81-97.

doi: https://doi.org/10.1007/s00005-012-0162-5

7. Boskovic G, Twining SS. Local control of alpha1-proteinase inhibitor levels: regulation of alpha1-proteinase inhibitor in the human cornea by growth factors and cytokines. Biochim Biophys Acta. 1998;1403(1):37-46.

doi: https://doi.org/10.1016/S0167-4889(98)00018-4

8. Ray MB, Desmet VJ, Gepts W. Alpha-1-antitrypsin immunoreactivity in islet cells of adult human pancreas. Cell Tissue Res. 1977;185(1):63-68. doi: https://doi.org/10.1007/BF00226668

9. Bosco D, Meda P, Morel P, et al. Expression and secretion of alpha1-proteinase inhibitor are regulated by proinflammatory cytokines in human pancreatic islet cells. Diabetologia. 2005;48(8):1523-1533.

doi: https://doi.org/10.1007/s00125-005-1816-1

10. Kalsheker N, Morley S, Morgan K. Gene regulation of the serine proteinase inhibitors alpha1-antitrypsin and alpha1antichymotrypsin. Biochem Soc Trans. 2002;30(2):93-98. doi: https://doi.org/10.1042/bst0300093
11. Perlmutter DH, Punsal PI. Distinct and additive effects of elastase and endotoxin on expression of alpha 1 proteinase inhibitor in mononuclear phagocytes. J Biol Chem. 1988;263(31):1649916503.

12. Knoell DL, Ralston DR, Coulter KR, Wewers MD. Alpha 1-antitrypsin and protease complexation is induced by lipopolysaccharide, interleukin-1beta, and tumor necrosis factor-alpha in monocytes. Am J Respir Crit Care Med. 1998; 157(1):246-255.

doi: https://doi.org/10.1164/ajrccm.157.1.9702033

13. Miyamoto Y, Akaike T, Alam MS, et al. Novel functions of human alpha(1)-protease inhibitor after S-nitrosylation: inhibition of cysteine protease and antibacterial activity. Biochem Biophys Res Commun. 2000;267(3):918-923.

doi: https://doi.org/10.1006/bbrc.1999.2046

14. Marciniuk DD, Hernandez P, Balter M, et al. Alpha-1 antitrypsin deficiency targeted testing and augmentation therapy: a Canadian Thoracic Society clinical practice guideline. Can Respir J. 2012;19(2):109-116. doi: https://doi.org/10.1155/2012/920918

15. Petrache I, Hajjar J, Campos M. Safety and efficacy of alpha-1antitrypsin augmentation therapy in the treatment of patients with alpha-1-antitrypsin deficiency. Biologics. 2009;3:193-204.

16. Song S, Morgan M, Ellis T, et al. Sustained secretion of human alpha-1-antitrypsin from murine muscle transduced with adeno-associated virus vectors. Proc Natl Acad Sci USA. 1998;95(24):14384-14388. doi: https://doi.org/10.1073/pnas.95.24.14384

17. Mueller C, Gernoux G, Gruntman AM, et al. 5 Year Expression and neutrophil defect repair after gene therapy in alpha-1 antitrypsin deficiency. Mol Ther. 2017;25(6):1387-1394.

18. Zhang B, Lu Y, Campbell-Thompson M, et al. Alpha1-antitrypsin protects beta-cells from apoptosis. Diabetes. 2007;56(5):13161323. doi: https://doi.org/10.2337/db06-1273

19. Petrache I, Fijalkowska I, Medler TR, et al. Alpha-1 antitrypsin inhibits caspase-3 activity, preventing lung endothelial cell apoptosis. Am J Pathol. 2006;169(4):1155-1166. doi: https://doi.org/10.2353/ajpath.2006.060058

20. Petrache I, Fijalkowska I, Zhen L, et al. A novel antiapoptotic role for alpha1-antitrypsin in the prevention of pulmonary emphysema. Am J Respir Crit Care Med. 2006;173(11):12221228. doi: https://doi.org/10.1164/rccm.200512-1842OC

21. Toldo S, Seropian IM, Mezzaroma E, et al. Alpha-1 antitrypsin inhibits caspase- 1 and protects from acute myocardial ischemiareperfusion injury. J Mol Cell Cardiol. 2011;51(2):244-251. doi: https://doi.org/10.1016/j.yjmcc.2011.05.003

22. Maes OC, Kravitz S, Mawal Y, et al. Characterization of alpha1antitrypsin as a heme oxygenase-1 suppressor in Alzheimer plasma. Neurobiol Dis. 2006;24(1):89-100. doi: https://doi.org/10.1016/j.nbd.2006.06.009 
23. Bergin DA, Reeves EP, Hurley K, et al. The circulating proteinase inhibitor alpha-1 antitrypsin regulates neutrophil degranulation and autoimmunity. Sci Transl Med. 2014;6(217):217ra1. doi: https://doi.org/10.1126/scitranslmed.3007116

24. Frenzel E, Wrenger S, Brugger B, et al. Alpha1-antitrypsin combines with plasma fatty acids and induces angiopoietin-like protein 4 expression. J Immunol. 2015;195(8):3605-3616. doi: https://doi.org/10.4049/jimmunol.1500740

$\overline{\text { 25. Karnaukhova E. Interactions of alpha1-proteinase inhibitor with }}$ small ligands of therapeutic potential: binding with retinoic acid. Amino Acids. 2010;38(4):1011-1020. doi: https://doi.org/10.1007/s00726-009-0309-9

26. Janciauskiene SM, Nita IM, Stevens T. Alpha1-antitrypsin, old dog, new tricks. Alpha1-antitrypsin exerts in vitro antiinflammatory activity in human monocytes by elevating cAMP. J Biol Chem. 2007;282(12):8573-8582. doi: https://doi.org/10.1074/jbc.M607976200

27. Zhang B, Lu Y, Campbell-Thompson M, et al. a1-antitrypsin protects $\beta$-cells from apoptosis. Diabetes. 2007;56(5):1316-1323. doi: https://doi.org/10.2337/db06-1273

28. Breit SN, Wakefield D, Robinson JP, Luckhurst E, Clark P, Penny R. The role of alpha 1-antitrypsin deficiency in the pathogenesis of immune disorders. Clin Immunol Immunopathol. 1985;35(3):363380. doi: https://doi.org/10.1016/0090-1229(85)90097-2

29. Breit SN, Penny R. The role of alpha 1 protease inhibitor (alpha 1 antitrypsin) in the regulation of immunologic and inflammatory reactions. Aust N Z J Med. 1980;10(4):449-453.

doi: https://doi.org/10.1111/j.1445-5994.1980.tb04101.x

30. Karsh J, Vergalla J, Jones EA. Alpha-1-antitrypsin phenotypes in rheumatoid arthritis and systemic lupus erythematosus. Arthritis Rheum. 1979;22(2):111-113.

doi: https://doi.org/10.1002/art.1780220202

31. Hall P, Tryon E, Nikolai TF, Roberts RC. Functional activities and nonenzymatic glycosylation of plasma proteinase inhibitors in diabetes. Clin Chim Acta. 1986;160(1):55-62. doi: https://doi.org/10.1016/0009-8981(86)90335-9

32. Sandler M, Gemperli BM, Hanekom C, Kuhn SH. Serum alpha 1-protease inhibitor in diabetes mellitus: reduced concentration and impaired activity. Diabetes Res Clin Pract. 1988;5(4):249255. doi: https://doi.org/10.1016/S0168-8227(88)80059-7

33. Hashemi M, Naderi M, Rashidi H, Ghavami S. Impaired activity of serum alpha-1-antitrypsin in diabetes mellitus. Diabetes Res Clin Pract. 2007;75(2):246-248.

doi: https://doi.org/10.1016/j.diabres.2006.06.020

34. Yaghmaei M, Hashemi M, Shikhzadeh A, Mokhtari M, Niazi A, Ghavami S. Serum trypsin inhibitory capacity in normal pregnancy and gestational diabetes mellitus. Diabetes Res Clin Pract. 2009;84(3):201-204.

doi: https://doi.org/10.1016/j.diabres.2009.03.003
35. Stone H, Pye A, Stockley RA. Disease associations in alpha-1antitrypsin deficiency. Respir Med. 2014;108(2):338-433. doi: https://doi.org/10.1016/j.rmed.2013.10.006

36. Geraminejad P, DeBloom JR, 2nd, Walling HW, Sontheimer RD, VanBeek M. Alpha-1-antitrypsin associated panniculitis: the MS variant. J Am Acad Dermatol. 2004;51(4):645-655. doi: https://doi.org/10.1016/j.jaad.2003.12.053

37. Johnson EF, Tolkachjov SN, Gibson LE. Alpha-1 antitrypsin deficiency panniculitis: clinical and pathologic characteristics of 10 cases. Int J Dermatol. 2018;57(8):952-958. doi: https://doi.org/10.1111/ijd.14012

38. Lyons PA, Rayner TF, Trivedi S, et al. Genetically distinct subsets within ANCA-associated vasculitis. New Eng J Med. 2012;367(3):214-223. doi: https://doi.org/10.1056/NEJMoa1108735

39. Xiao H, Hu P, Falk RJ, Jennette JC. Overview of the Pathogenesis of ANCA-Associated Vasculitis. Kidney Dis (Basel). 2016;1(4):205-215. doi: https://doi.org/10.1159/000442323

40. Rooney CP, Taggart C, Coakley R, McElvaney NG, O’Neill SJ. Anti-proteinase 3 antibody activation of neutrophils can be inhibited by alpha1-antitrypsin. Am J Respir Cell Mol Biol. 2001;24(6):747-754.

doi: https://doi.org/10.1165/ajrcmb.24.6.4147

41. Mota A, Sahebghadam Lotfi A, Jamshidi AR, Najavand S. Alpha 1-antitrypsin activity is markedly decreased in Wegener's granulomatosis. Rheumatol Int. 2014;34(4):553-558. doi: https://doi.org/10.1007/s00296-013-2745-9

42. Cosio MG, Bazzan E, Rigobello C, et al. Alpha-1 antitrypsin deficiency: beyond the protease/antiprotease paradigm. Ann Am Thorac Soc. 2016;13 (Suppl 4):S305-310.

doi: https://doi.org/10.1513/AnnalsATS.201510-671KV

43. Baraldo S, Turato G, Lunardi F, et al. Immune activation in alpha1-antitrypsin-deficiency emphysema. Beyond the protease-antiprotease paradigm. Am J Respir Crit Care Med. 2015; 191(4):402-409.

doi: https://doi.org/10.1164/rccm.201403-05290C

44. Song S, Goudy K, Campbell-Thompson M, et al. Recombinant adeno-associated virus-mediated alpha-1 antitrypsin gene therapy prevents type I diabetes in NOD mice. Gene Ther. 2004;11(2):181-186. doi: https://doi.org/10.1038/sj.gt.3302156

45. Flotte TR, Trapnell BC, Humphries M, et al. Phase 2 clinical trial of a recombinant adeno-associated viral vector expressing alpha1antitrypsin: interim results. Hum Gene Ther. 2011;22(10):12391247. doi: https://doi.org/10.1089/hum.2011.053

46. Brantly ML, Spencer LT, Humphries M, et al. Phase I trial of intramuscular injection of a recombinant adeno-associated virus serotype 2 alphal-antitrypsin (AAT) vector in AAT-deficient adults. Hum Gene Ther. 2006;17(12):1177-1186. doi: https://doi.org/10.1089/hum.2006.17.1177 
47. Flotte TR, Brantly ML, Spencer LT, et al. Phase I trial of intramuscular injection of a recombinant adeno-associated virus alpha 1-antitrypsin (rAAV2-CB-hAAT) gene vector to AAT-deficient adults. Hum Gene Ther. 2004;15(1):93-128. doi:https://doi.org/10.1089/10430340460732490

48. Magenau JM, Goldstein SC, Peltier D, et al. Alpha1-antitrypsin infusion for treatment of steroid-resistant acute graft-versushost disease. Blood. 2018;131(12):1372-1379. doi: https://doi.org/10.1182/blood-2017-11-815746

49. Moldthan HL, Hirko AC, Thinschmidt JS, et al. Alpha 1-antitrypsin therapy mitigated ischemic stroke damage in rats. J Stroke Cerebrovasc Dis. 2014. 23(5):e355-363. doi: https://doi.org/10.1016/j.jstrokecerebrovasdis.2013.12.029

50. Cao JJ, Gregoire BR, Sun L, Song S. Alpha- 1 antitrypsin reduces ovariectomy-induced bone loss in mice. Ann N Y Acad Sci. 2011;1240:E31-35.

doi: https://doi.org/10.1111/j.1749-6632.2011.06370.x

51. Akbar MA, Cao JJ, Lu Y, et al. Alpha-1 antitrypsin gene therapy ameliorates bone loss in ovariectomy-induced osteoporosis mouse model. Hum Gene Ther. 2016;27(9):67986. doi: https://doi.org/10.1089/hum.2016.029

52. Yuan Y, DiCiaccio B, Li Y, et al. Anti-inflammaging effects of human alpha-1 antitrypsin. Aging Cell. 2018;17(1). doi: https://doi.org/10.1111/acel.12694 .

53. von Herrath MG, Korsgren $\mathrm{O}$, Atkinson MA. Factors impeding the discovery of an intervention-based treatment for type 1 diabetes. Clin Exp Immunol. 2016;183(1):1-7. doi: https://doi.org/10.1111/cei.12656

54. Goudy K, Song S, Wasserfall C, et al. Adeno-associated virus vector-mediated IL-10 gene delivery prevents type 1 diabetes in NOD mice. Proc Natl Acad Sci USA. 2001;98(24):13913-13918. doi: https://doi.org/10.1073/pnas.251532298

55. Lu Y, Choi YK, Campbell-Thompson M, et al. Therapeutic level of functional human alpha 1 antitrypsin (hAAT) secreted from murine muscle transduced by adeno-associated virus (rAAV1) vector. J Gene Med. 2006;8(6):730-705.

doi: https://doi.org/10.1002/jgm.896

56. Lu Y, Tang M, Wasserfall $C$, et al. Alpha1-antitrypsin gene therapy modulates cellular immunity and efficiently prevents type 1 diabetes in nonobese diabetic mice. Hum Gene Ther. 2006; 17(6):625-634.

doi: https://doi.org/10.1089/hum.2006.17.625

57. $\mathrm{Ma} \mathrm{H}, \mathrm{Lu} \mathrm{Y}$, Li H, et al. Intradermal alpha1-antitrypsin therapy avoids fatal anaphylaxis, prevents type 1 diabetes and reverses hyperglycaemia in the NOD mouse model of the disease. Diabetologia. 2010;53(10):2198-2204. doi: https://doi.org/10.1007/s00125-010-1829-2
58. Koulmanda M, Bhasin M, Hoffman L, et al. Curative and beta cell regenerative effects of alpha1-antitrypsin treatment in autoimmune diabetic NOD mice. Proc Natl Acad Sci USA. 2008; 105(42):16242-16247.

doi: https://doi.org/10.1073/pnas.0808031105

59. Lu Y, Parker M, Pileggi A, et al. Human alpha 1-antitrypsin therapy induces fatal anaphylaxis in non-obese diabetic mice. Clin Exp Immunol. 2008;154(1):15-21. doi: https://doi.org/10.1111/j.1365-2249.2008.03721.x

60. Kalis M, Kumar R, Janciauskiene S, Salehi A, Cilio CM. Alpha 1-antitrypsin enhances insulin secretion and prevents cytokine-mediated apoptosis in pancreatic beta-cells. Islets. 2010;2(3):185-189. doi: https://doi.org/10.4161/isl.2.3.11654

61. Weir GC, Ehlers MR, Harris KM, et al. Alpha-1 antitrypsin treatment of new-onset type 1 diabetes: An open-label, phase I clinical trial (RETAIN) to assess safety and pharmacokinetics. Pediatr Diabetes. 2018;19(5):945-954. doi:. https://doi.org/10.1111/pedi.12660

62. Lewis EC, Shapiro L, Bowers OJ, Dinarello CA. Alpha1antitrypsin monotherapy prolongs islet allograft survival in mice. Proc Natl Acad Sci USA. 2005;102(34):12153-12158. doi: https://doi.org/10.1073/pnas.0505579102

63. Lewis EC, Mizrahi M, Toledano M, et al. Alpha1-antitrypsin monotherapy induces immune tolerance during islet allograft transplantation in mice. Proc Natl Acad Sci USA. 2008;105(42):16236-16241.

doi: https://doi.org/10.1073/pnas.0807627105

64. Wang J, Sun Z, Gou W, et al. Alpha-1 antitrypsin enhances islet engraftment by suppression of instant blood-mediated inflammatory reaction. Diabetes. 2017;66(4):970-980. doi: https://doi.org/10.2337/db16-1036

65. Grimstein C, Choi YK, Wasserfall CH, et al. Alpha-1 antitrypsin protein and gene therapies decrease autoimmunity and delay arthritis development in mouse model. J Transl Med. 2011;9:21. doi: https://doi.org/10.1186/1479-5876-9-21

66. Lu Y, Song S. Distinct immune responses to transgene products from rAAV1 and rAAV8 vectors. Proc Natl Acad Sci USA. 2009; 106(40):17158-17162.

doi: https://doi.org/10.1073/pnas.0909520106

67. Grimstein C, Choi YK, Satoh M, et al. Combination of alpha-1 antitrypsin and doxycycline suppresses collagen-induced arthritis. J Gene Med. 2010;12(1):35-44. doi: https://doi.org/10.1002/jgm.1409

68. Cox DW, Huber O. Rheumatoid arthritis and alpha-1-antitrypsin. Lancet. 1976;1(7971):1216-1217.

69. Papiha SS, Pal B, Walker D, Mangion P, Hossain MA. Alpha 1 antitrypsin (PI) phenotypes in two rheumatic diseases: a reappraisal of the association of PI subtypes in rheumatoid arthritis. Ann Rheum Dis. 1989;48(1):48-52. doi: https://doi.org/10.1136/ard.48.1.48 
70. Abboud RT, Chalmers A, Gofton JP, Richter AM, Enarson DA. Relationship between severity of rheumatoid arthritis and serum alpha 1-antitrypsin. J Rheumatol Suppl. 1991;18(10):1490-1495.

71. McCarthy C, Orr C, Fee LT, et al. Brief report: genetic variation of the alpha 1 -antitrypsin gene is associated with increased autoantibody production in rheumatoid arthritis. Arthritis Rheum. 2017;69(8):1576-1579.

doi: https://doi.org/10.1002/art.40127

72. Verheul MK, Yee A, Seaman A, et al. Identification of carbamylated alpha 1 anti-trypsin (A1AT) as an antigenic target of anti-CarP antibodies in patients with rheumatoid arthritis. $J$ Autoimmun. 2017;80:77-84.

doi: https://doi.org/10.1016/j.jaut.2017.02.008

73. Vincent FB, Morand EF, Schneider P, Mackay F. The BAFF/ APRIL system in SLE pathogenesis. Nat Rev Rheumatol. 2014:365-373.

74. Mackern-Oberti JP, Llanos C, Vega F, et al. Role of dendritic cells in the initiation, progress and modulation of systemic autoimmune diseases. Autoimmun Rev. 2015;14(2):127-39. doi: https://doi.org/10.1016/j.autrev.2014.10.010

75. Suurmond J, Zou YR, Kim SJ, Diamond B. Therapeutics to block autoantibody initiation and propagation in systemic lupus erythematosus and rheumatoid arthritis. Sci Transl Med. 2015;7(280):280ps5.

doi: https://doi.org/10.1126/scitranslmed.aaa3809

76. Svenungsson E, Jensen-Urstad K, Heimburger $M$, et al. Risk factors for cardiovascular disease in systemic lupus erythematosus. Circulation. 2001;104(16):1887-1893.

doi: https://doi.org/10.1161/hc4101.097518

77. Shapira E, Proscura E, Brodsky B, Wormser U. Novel peptides as potential treatment of systemic lupus erythematosus. Lupus. 2011;20(5):463-472.

doi: https://doi.org/10.1177/0961203310389484

78. Elshikha AS, Lu Y, Chen MJ, et al. Alpha 1 antitrypsin inhibits dendritic cell activation and attenuates nephritis in a mouse model of lupus. PloS One. 2016;11(5):e0156583.

doi: https://doi.org/10.1371/journal.pone.0156583

79. Karadagi A, Johansson H, Zemack H, et al. Exogenous alpha 1-antitrypsin down-regulates SERPINA1 expression. PloS One. 2017;12(5):e0177279.

doi: https://doi.org/10.1371/journal.pone.0177279

80. Kolarich D, Weber A, Turecek PL, Schwarz HP, Altmann F. Comprehensive glyco-proteomic analysis of human alpha1antitrypsin and its charge isoforms. Proteomics. 2006;6(11):336980. doi: https://doi.org/10.1002/pmic.200500751

81. Mills K, Mills PB, Clayton PT, Johnson AW, Whitehouse DB, Winchester BG. Identification of alpha(1)-antitrypsin variants in plasma with the use of proteomic technology. Clin Chem. 2001;47(11):2012-2022.
82. Bergin DA, Reeves EP, Meleady P, et al. Alpha-1 antitrypsin regulates human neutrophil chemotaxis induced by soluble immune complexes and IL-8. J Clin Invest. 2010;120(12):42364250. doi: https://doi.org/10.1172/JCI41196

83. McCarthy C, Saldova R, O’Brien ME, et al. Increased outer arm and core fucose residues on the N-glycans of mutated alpha-1 antitrypsin protein from alpha-1 antitrypsin deficient individuals. J Proteome Res. 2014;13(2):596-605. doi: https://doi.org/10.1021/pr400752t

84. Sarrats A, Saldova R, Pla E, et al. Glycosylation of liver acutephase proteins in pancreatic cancer and chronic pancreatitis. Proteomics Clin Appl. 2010;4(4):432-448. doi: https://doi.org/10.1002/prca.200900150

85. McCarthy C, Dunlea DM, Saldova R, et al. Glycosylation repurposes alpha-1 antitrypsin for resolution of communityacquired pneumonia. Am J Respir Crit Care Med. 2018;197(10): 1346-1349.

doi: https://doi.org/10.1164/rccm.201709-1954LE

86. Taggart C, Cervantes-Laurean D, Kim G, et al. Oxidation of either methionine 351 or methionine 358 in alpha 1-antitrypsin causes loss of anti-neutrophil elastase activity. J Biol Chem. 2000;275(35):27258-27265

87. Wong PS, Travis J. Isolation and properties of oxidized alpha1-proteinase inhibitor from human rheumatoid synovial fluid. Biochem Biophys Res Commun. 1980;96(3):1449-1454. doi: https://doi.org/10.1016/0006-291X(80)90113-8

88. Mashiba S, Wada Y, Takeya M, et al. In vivo complex formation of oxidized alpha(1)-antitrypsin and LDL. Arterioscler Thromb Vasc Biol. 2001;21(11):1801-1808. doi: https://doi.org/10.1161/hq1101.098232

89. Liu Z, Zhou X, Shapiro SD, et al. The serpin alpha1-proteinase inhibitor is a critical substrate for gelatinase B/MMP-9 in vivo. Cell. 2000;102(5):647-655. doi: https://doi.org/10.1016/S0092-8674(00)00087-8

90. Ram M, Sherer Y, Shoenfeld Y. Matrix metalloproteinase-9 and autoimmune diseases. J Clin Immunol. 2006;26(4):299-307.

91. Mansuy-Aubert V, Zhou QL, Xie X, et al. Imbalance between neutrophil elastase and its inhibitor alpha1-antitrypsin in obesity alters insulin sensitivity, inflammation, and energy expenditure. Cell Metab. 2013;17(4):534-548.

doi: https://doi.org/10.1016/j.cmet.2013.03.005

92. Wang Y, Xiao Y, Zhong L, et al. Increased neutrophil elastase and proteinase 3 and augmented NETosis are closely associated with beta-cell autoimmunity in patients with type 1 diabetes. Diabetes. 2014;63(12):4239-4248. doi: https://doi.org/10.2337/db14-0480 
93. O’Dwyer CA, O'Brien ME, Wormald MR, et al. The BLT1 Inhibitory function of alpha- 1 antitrypsin augmentation therapy disrupts leukotriene b4 neutrophil signaling. $J$ Immunol. 2015; 195(8):3628-3641.

doi: https://doi.org/10.4049/jimmunol.1500038

94. Kim ND, Chou RC, Seung E, Tager AM, Luster AD. A unique requirement for the leukotriene $\mathrm{B} 4$ receptor BLT1 for neutrophil recruitment in inflammatory arthritis. J Exp Med. 2006;203(4):829-835. doi: https://doi.org/10.1084/jem.20052349

95. Seggev JS, Thornton WH, Jr., Edes TE. Serum leukotriene B4 levels in patients with obstructive pulmonary disease. Chest. 1991;99(2):289-291. doi: https://doi.org/10.1378/chest.99.2.289

96. Hashimoto A, Endo H, Hayashi I, et al. Differential expression of leukotriene B4 receptor subtypes (BLT1 and BLT2) in human synovial tissues and synovial fluid leukocytes of patients with rheumatoid arthritis. J Rheumatol. 2003;30(8):1712-1718.

$\overline{\text { 97. Iversen L, Kragballe K, Ziboh VA. Significance of leukotriene-A4 }}$ hydrolase in the pathogenesis of psoriasis. Skin Pharmacol. 1997;10(4):169-177. doi: https://doi.org/10.1159/000211501

98. Finotti P, Pagetta A. A heat shock protein70 fusion protein with alpha1-antitrypsin in plasma of type 1 diabetic subjects. Biochem Biophys Res Commun. 2004;315(2):297-305. doi: https://doi.org/10.1016/j.bbrc.2004.01.058

99. Pagetta A, Folda A, Brunati AM, Finotti P. Identification and purification from the plasma of Type 1 diabetic subjects of a proteolytically active Grp94Evidence that Grp94 is entirely responsible for plasma proteolytic activity. Diabetologia. 2003;46(7):996-1006.

doi: https://doi.org/10.1007/s00125-003-1133-5

100. Li Z, Menoret A, Srivastava P. Roles of heat-shock proteins in antigen presentation and cross-presentation. Curr Opin Immunol. 2002;14(1):45-51.

doi: https://doi.org/10.1016/S0952-7915(01)00297-7

$\overline{\text { 101. Henry CJ, Casas-Selves M, Kim J, et al. Aging-associated }}$ inflammation promotes selection for adaptive oncogenic events in B cell progenitors. J Clin Invest. 2015;125(12):4666-80. doi: https://doi.org/10.1172/JCI83024

102. Ozeri E, Mizrahi M, Shahaf G, Lewis EC. Alpha-1 antitrypsin promotes semimature, IL-10-producing and readily migrating tolerogenic dendritic cells. J Immunol. 2012;189(1):146-153. doi: https://doi.org/10.4049/jimmunol.1101340 